\title{
A Review of Literature on Human Behaviour and Artificial Intelligence: Contributions Towards Knowledge Management
}

\author{
Elizabeth Real de Oliveira and Pedro Rodrigues \\ Universidade Lusíada - Norte, Portugal \\ mereal@por.ulusiada.pt \\ pedrorodrigues@por.ulusiada.pt
}

\begin{abstract}
The main purpose of this research paper is to understand how artificial intelligence and machine learning applied to human behaviour has been treated, both theoretically and empirically, over the last twenty years, regarding predictive analytics and human organizational behaviour analysis. To achieve this goal, the authors performed a systematic literature review, as proposed by Tranfield, Denyer and Smart (2003), on selected databases and followed the PRISMA framework (Preferred Reporting Items for Systematic reviews and Meta-Analyses). The method is particularly suited for assessing emerging trends within multiple disciplines and therefore deemed the most suitable method for the purposes of this paper, which intends to survey and select papers according to their contribute towards theory building. By mapping what is known, this review will lay the groundwork, providing a timely insight into the current state of research on human organisational behaviour and its applications. A total of 17795 papers resulted from the application of the search equations. The papers' abstracts were screened according to the inclusion / exclusion criterions which resulted in 199 papers for analysis. The authors have analysed the papers through VOSviewer software and R programming statistical computing software. This review showed that $60 \%$ of the research undertaken in the field has been done in the last three and a half years and there is no prominent author or academic journal, showing the emergence and the novelty of this research. The other key finds of the research relate to the evolution of the concept, from data-driven (hard) towards emotions-driven (soft) organisations.
\end{abstract}

Keywords: Human Behaviour, Big Data, Artificial Intelligence, Knowledge Management and Creation

\section{Introduction}

Understanding human behaviour has been crucial for businesses, for as long as businesses exist. How to unveil people behaviour regarding motivation, engagement, and loyalty towards a company? How to gain deeper insights into your customers wants and desires? Creating useful knowledge for businesses to act upon and build strategies is no longer a mirage if you consider how much technology has helped us in the last twenty years.

To shed some light into this body of knowledge, the authors undertook a systematic literature review focusing published academic research, which addressed the understanding of human behaviour through artificial intelligence, machine learning and the application of neurosciences tools.

The first moment in history where machines were viewed as having intelligence was when in 1950, Turing ${ }^{1}$ published his seminal article "Computing Machinery and Intelligence" where he described how to create intelligent machines, in particular, how to test their intelligence. This Turing Test is still considered today as a benchmark to identify intelligence of an artificial system (when a human interacts with another human and a machine and we are unable to distinguish the machine from the human). Today artificial neural networks and deep learning form the basis of most applications we know, they are the basis of image recognition algorithms used by Facebook, speech recognition algorithms that fuel smart speakers and self-driving cars (Haenlein \& Kaplan, 2019).

We are surrounded by data, which is useless, unless it can be transformed into information, which then must be transformed into knowledge. Big data is in fact a big buzzword in recent years. Nevertheless, as described in a recent editorial from the Academy of Management Journal written by Simsek and colleagues (2019) there still is a great deal of ambiguity and even confusion on what Big Data is and what it means for organizational and management researchers.

Taming big data an artificial intelligence through machine learning can be the key to address many management issues, such as, how to identify real talent within and for your organization, knowing when your best employee is about to quit, predict consumer preferences and address unique consumer differences, amongst many others.

${ }^{1}$ Alan Turing, “Computing Machinery and Intelligence," Mind, LIX/236 (1950): 433-460 
According to Hoeschl and Barcellos (2006, p. 12) "the possibility of translating human intelligence to plastic artificial base has a clear limit: If intelligence can be generated from these elements, it must be necessarily different from human one, because results happen from different human elements." Also, to materialize knowledge (to safeguard it) one must find a way to manipulate, store and transmit it within the organisation. These authors name this as the biggest challenge of Al intelligent solutions over of the last decades.

In the original science fiction film Blade Runner, directed by Ridley Scott in 1982, and later in its sequel Blade Runner 2049, an interesting philosophical dilemma is put forwarded: are robots able to feel emotions? And if so, what makes us humans? The film set in a dystopian future, creates an interesting conundrum since humans develop machines that replicate humans but give them a date of expiration (they have a four-year life span) to enslave them to perform tasks humans do not want to do. The dilemma of "humanity" reaches its peak at the end monologue, performed by the character Roy Batty, entitled "tears on the rain" 2 . At this moment, the machine / human saves the life of its human prosecutor while sheds "invisible" tears on the rain, while his lifespan is ending. These replicants were created as adults but memories of growing up were implanted in their brains. These memories allowed them to feel empathy towards humans and develop emotions.

Where do we establish the limits? The knowledge that can be generated through Al and machine learning and the possibilities that it creates to generate more knowledge is a huge challenge for organisations and societies. Across different scientific areas researchers are on the verge of taming the challenges of the usage of $\mathrm{Al}$ for better performances. For businesses Al represents productivity, efficiency, but also new ways to do things to innovate and break barriers. Knowledge that creates knowledge in a Fibonacci spiral ${ }^{3}$.

Inspired by these thoughts the authors raise the following questions: how artificial intelligence, machine learning, big data and neurosciences, applied to human behaviour, have been treated, both theoretically and empirically, over the last twenty years, regarding creating knowledge through predictive analytics and human organizational behaviour? How this field of research has been applied to create, retain, and develop knowledge within organisations?

\section{Research Methodology}

The aim of this research is to present the evolution of studies regarding human behaviour within organisations and highlight the relevance of new research intending to inspire research ideas by recognizing gaps or inconsistencies (Cronin, 2008) and/or creating theoretical frameworks (Coughlan, 2007). For this study, the authors followed the proposed methodology and process for conducting systematic literature reviews by Tranfield, Denyer, and Smart (2003). For verifying each step of the process the PRISMA guidelines were also adopted. This is a well-establish method aimed at systematizing knowledge in an orderly and consistent way, increasing its efficiency and effectiveness pro the generated output. PRISMA allows to systematize information verification practices, justifying all inputs and outputs, that is, papers included and excluded. This is a six steps method including, definition of research question and inclusion/exclusion criteria; collecting and selection of the studies; extracting and presenting the most relevant information and data; analysing and synthesizing information (Moher et al, 2009).

The database chosen for collecting data was B-On (the online knowledge library) since allows access to full texts from over 16,750 scientific international publications from 16 publishers, including the web of knowledge (Wok). To apply the search equations (combination between keywords), the following limitations within B-On were used: a) disciplines: economics; business and management, marketing; and sociology; b) restricted to access to full text; c) timespan: from 2000 until 2020 (current date); d) only peer reviewed journals.

The search equations were applied, and the researchers conducted an initial rigorous screening based on the article tittle, keywords and abstract. To be included on the database papers had to address human behaviour within organizations and to address how this behaviour was studied or understood through predictive analytics, neurosciences, big data, artificial intelligence, or machine learning.

Search equations, initial results and final selection numbers can be seen in the following table.

\footnotetext{
${ }^{2}$ Film's original monologue: "I've seen things you people wouldn't believe. Attack ships on fire off the shoulder of Orion. I watched C-beams glitter in the dark near the Tannhäuser Gate. All those moments will be lost in time, like tears in rain. Time to die."

${ }^{3}$ In mathematics, the Fibonacci numbers, commonly denoted $F_{n}$, form a sequence, called the Fibonacci sequence, such that each number is the sum of the two preceding ones, starting from 0 and 1 . This is commonly known as the golden number.
} 
Table 1: Search equations

\begin{tabular}{|c|c|c|}
\hline Search Equation & Results & Selection \\
\hline Artificial Intelligence and Machine Learning & 2817 & 6 \\
\hline Artificial Intelligence and Human behavior & 298 & 13 \\
\hline Artificial Intelligence and Human behaviour & 361 & 9 \\
\hline Artificial Intelligence and Human profiling & 2 & 2 \\
\hline Artificial Intelligence and Predictive Analytics & 225 & 6 \\
\hline Artificial Intelligence and Big Data & 394 & 5 \\
\hline Artificial Intelligence and Neurosciences & 90 & 5 \\
\hline Artificial Intelligence and Knowledge Management & 724 & 5 \\
\hline Artificial Intelligence and Knowledge Creation & 46 & 5 \\
\hline Artificial Intelligence and Gaming & 32 & 5 \\
\hline Machine Learning and Human behavior & 298 & 6 \\
\hline Machine Learning and Human behaviour & 339 & 3 \\
\hline Machine Learning and Human profiling & 10 & 1 \\
\hline Machine Learning and Predictive Analytics & 117 & 5 \\
\hline Machine Learning and Big Data & 810 & 5 \\
\hline Machine Learning and Neurosciences & 117 & 7 \\
\hline Machine Learning and Knowledge Management & 821 & 5 \\
\hline Machine Learning and Knowledge Creation & 42 & 3 \\
\hline Machine Learning and Gaming & 28 & 5 \\
\hline Human behavior and Human profiling & 132 & 5 \\
\hline Human behaviour and Human profiling & 138 & 3 \\
\hline Human behavior and Predictive Analytics & 23 & 3 \\
\hline Human behaviour and Predictive Analytics & 23 & 3 \\
\hline Human behavior and Big Data & 177 & 3 \\
\hline Human behaviour and Big Data & 177 & 3 \\
\hline Human behavior and Neurosciences & 673 & 2 \\
\hline Human behaviour and Neurosciences & 673 & 3 \\
\hline Human behavior and Knowledge Management & 1791 & 3 \\
\hline Human behaviour and Knowledge Management & 1767 & 3 \\
\hline Human behavior and Knowledge Creation & 115 & 3 \\
\hline Human behaviour and Knowledge Creation & 114 & 3 \\
\hline Human behavior and Gaming & 246 & 3 \\
\hline Human behaviour and Gaming & 246 & 2 \\
\hline Human profiling and Predictive Analytics & 0 & 0 \\
\hline Human profiling and Big Data & 5 & 5 \\
\hline Human profiling and Neurosciences & 6 & 4 \\
\hline Human profiling and Knowledge Management & 15 & 5 \\
\hline Human profiling and Knowledge Creation & 1 & 0 \\
\hline Human profiling and Gaming & 1 & 1 \\
\hline Predictive Analytics and Big Data & 180 & 5 \\
\hline Predictive Analytics and Neurosciences & 2 & 2 \\
\hline Predictive Analytics and Knowledge Management & 48 & 5 \\
\hline Predictive Analytics and Knowledge Creation & 2 & 1 \\
\hline Predictive Analytics and Gaming & 1 & 1 \\
\hline Big Data and Neurosciences & 18 & 4 \\
\hline
\end{tabular}




\begin{tabular}{|c|c|c|}
\hline Search Equation & Results & Selection \\
\hline Big Data and Knowledge Management & 596 & 5 \\
\hline Big Data and Knowledge Creation & 29 & 5 \\
\hline Big Data and Gaming & 16 & 2 \\
\hline Neurosciences and Knowledge Management & 84 & 4 \\
\hline Neurosciences and Knowledge Creation & 5 & 2 \\
\hline Neurosciences and Gaming & 41 & 3 \\
\hline Knowledge Management and Knowledge Creation & 2858 & 4 \\
\hline Knowledge Creation and Gaming & 21 & 3 \\
\hline Totals & 17795 & 204 \\
\hline
\end{tabular}

After elimination of duplicates a total of 199 articles were included in our analysis. The authors opted to keep the search equations quite open, since if they narrowed them down, for example: Neurosciences and Knowledge Creation and Machine Learning results would be zero. Instead, we have considered it useful to have broader search equations, such as: knowledge management and knowledge creation $(n=2858)$ and then screening the abstracts for relevance. Also, the noun "behaviour" was spelled in the American and British forms to encompass all possible results.

The next steps were to conduct descriptive statistics (using VOSviewer and R programming) and content analysis that will be described in the next section.

\section{Research Findings}

An analysis of the database showed that $60 \%$ of work published by researchers happened after 2016 . Between the year 2000 and 2015 the average publication regarding these topics were 5,25 papers a year, while between 2017 and 2019 the average was 30 papers a year. This demonstrates an increasing interest on the topic, around 30 papers a year, nevertheless this amount still represents a very short number of articles on a specific subject.

\subsection{Cluster Analysis using VOSviewer and R Programming}

The VOSviewer software is a tool for constructing and visualizing bibliometric networks and $\mathrm{R}$ is a language and environment for statistical computing and graphics. The authors have analyzed the outputs from the filtered search equations (199 articles) and results are presented in the following figures (network and density graphs).

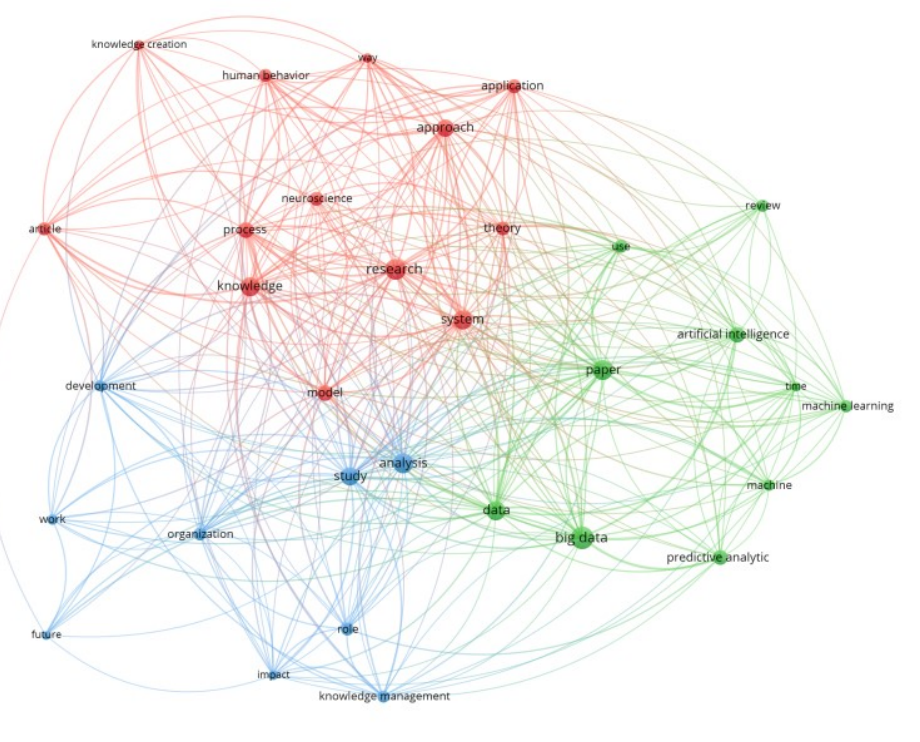




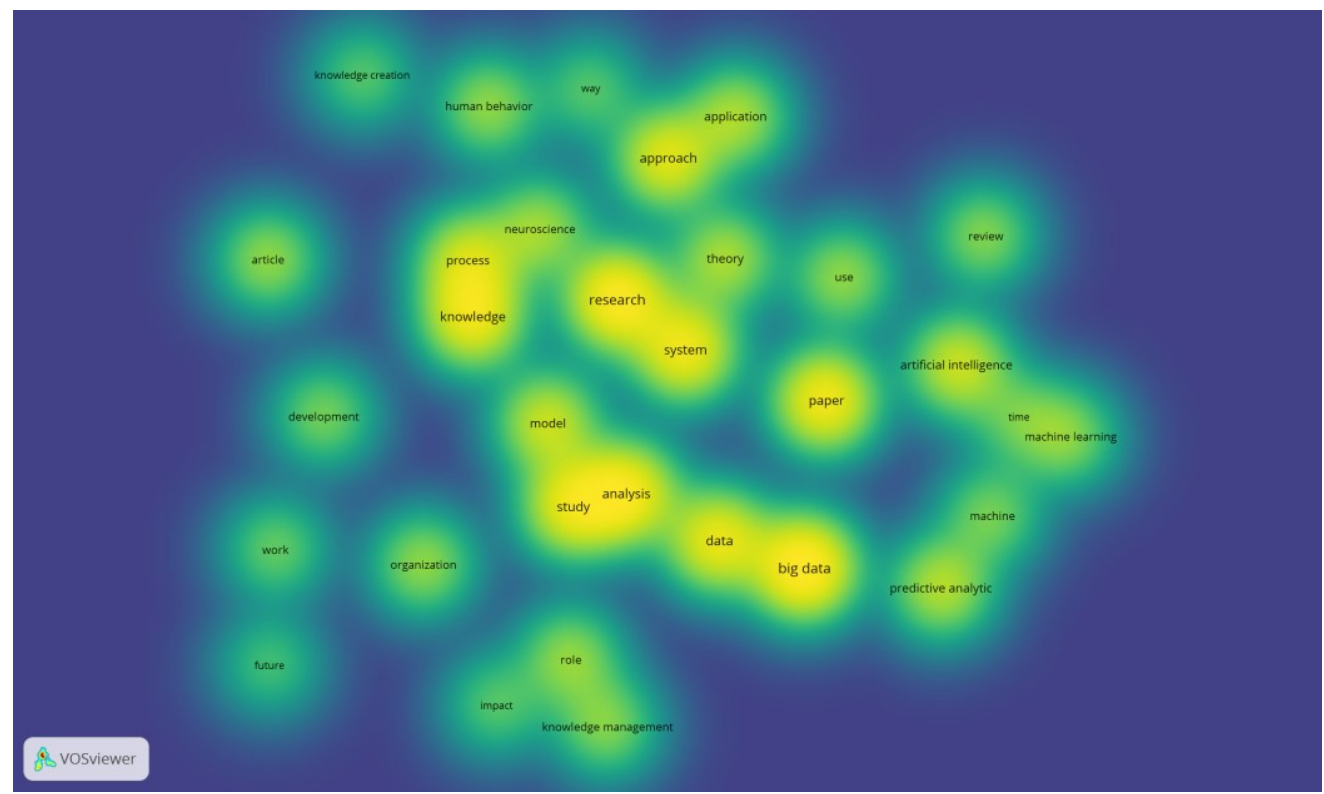

Figures 1 and 2: VOSviewer Network and Density Graph

To produce an analysis of the network graph, the authors did not considered words such as paper, article and research, which were mentioned several times due to the nature of the sources (and could not be eliminated from the software). Looking at the network graph, one can see the existence of 3 main clusters that can be identified by the intensity of relationships and size of the density (showed in yellow) characterized by the words analysis, knowledge, and big data. One might deduce that the Big Data cluster reflects the great scientific production around this theme, with direct relationships with artificial intelligence, machine learning and predictive analytics. In the analysis cluster, there is a strong relationship index with concepts such as, organization, role and knowledge management, driving the future. The knowledge cluster has a strong association with neurosciences studies, human behaviour and knowledge creation. The VOSviewer network graph also shows the opposite positioning of knowledge creation and knowledge management, where knowledge management is closely associated with big data and, on the other hand, knowledge creation is closely associated with knowledge and human behavior, positioned relatively far from the topic of big data.

An annual scientific production chart was also produced (using R programming).

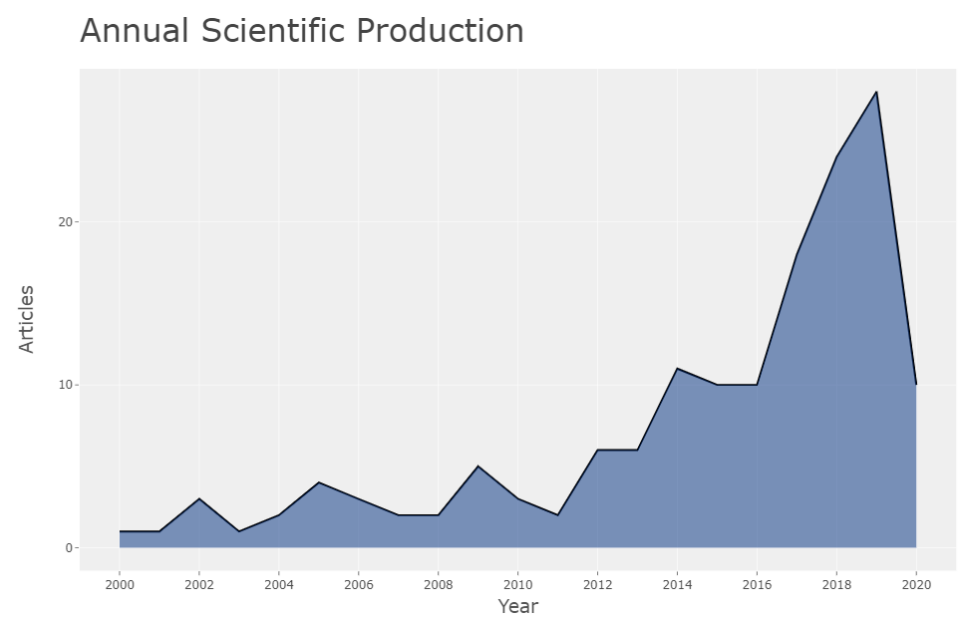

Figure 3: Annual Scientific Production Chart

According to the Annual Scientific Production Growth Chart, we can detect a steady but slow production rate until 2006, with an increment from 2016 that reaches its peak in the year 2019. The year 2020 is an enigma mainly due to the pandemic period, that started in the beginning of the year, which could cause delays in publications and that may not indicate a decrease interest on the topic. 


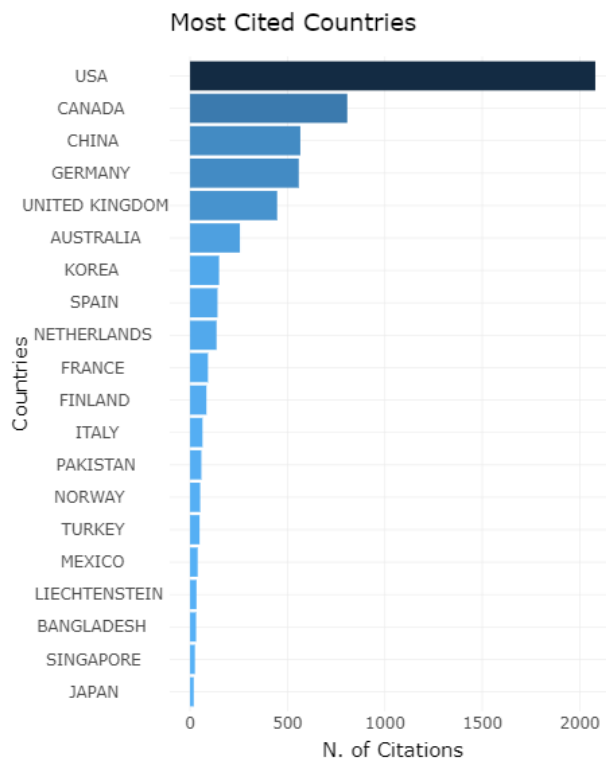

Figure 5: Most Cited Countries Chart

According to the most cited countries chart, USA is found to be the country with the largest scientific production, followed by Canada and China, whereas only two European countries appear in the top 6, Germany and the United Kingdom, respectively. To understand the differences between countries the authors analyzed the Delloite Report "Future in the balance? How countries are pursuing an Al advantage" ${ }^{4}$ (2019). According to this report "for years, the United States has been a leader in public and private Al research. Consider the last several years of venture capital investment in the Al sector. In 2012, venture capitalists funded US\$282 million in Al initiatives, and that number skyrocketed to US\$5 billion by 2017 . The following year, Al investments by VCS topped US\$8 billion" (p. 15). Canada and China are also mentioned in this report, although Canada is appointed as having a cautious approach to the application of Al since "they confront a host of issues regarding ethical implications, enhanced cyber vulnerabilities, and questions of talent readiness" (p.10). Pertain to China its "government has declared its ambition to become the world's leading Al innovator by 2030" (p.11).

According to this survey "no matter where organizations are on their Al journeys, their approach to tackling these questions varies. Some are playing catch-up with their global rivals. Others are addressing their aims through focused projects, or by pursuing larger-scale initiatives. Some early adopters are much more focused on training and skills development than others" (p. 16). "There's clearly no one-size-fits-all approach to adopting and integrating Al. Al-fuelled transformation of businesses and industries appears to be coming rapidly, and the window for differentiation is shrinking. Much hangs in the balance-including the future competitiveness of companies and even whole countries" (p. 17).

${ }^{4}$ Delloite Insights Report consulted on $20^{\text {th }}$ March in https://www2.deloitte.com/content/dam/Deloitte/lu/Documents/public-sector/luglobal-ai-survey.pdf 


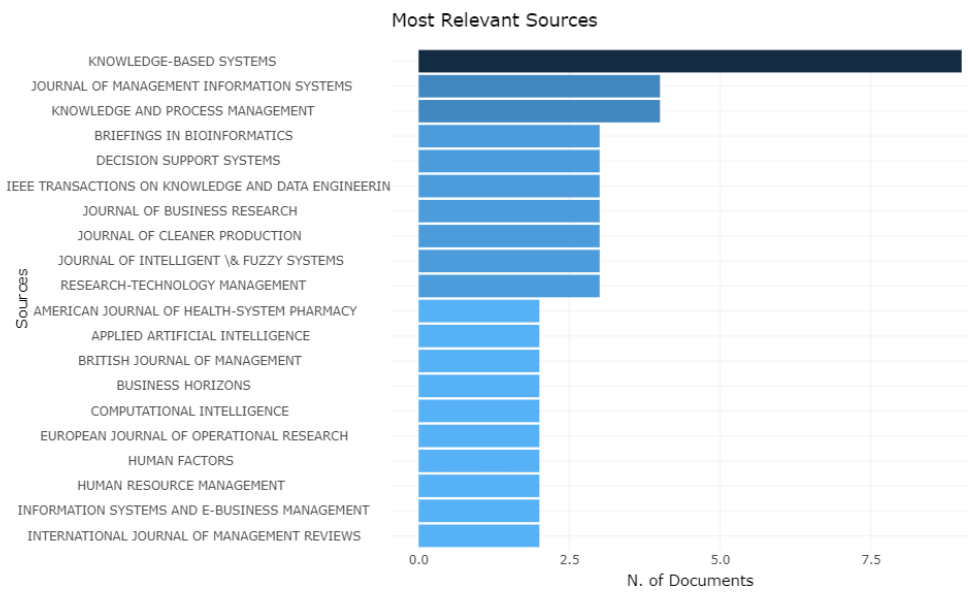

Figure 6: Most Relevant Sources Chart

According to the most relevant sources chart, we found that the Journal of Knowledge-Based Systems is the source that has the most relevant publications, with almost twice as many relevant publications as competitors, followed by the Journal of Management Information Systems and Knowledge and Process Management Journal.

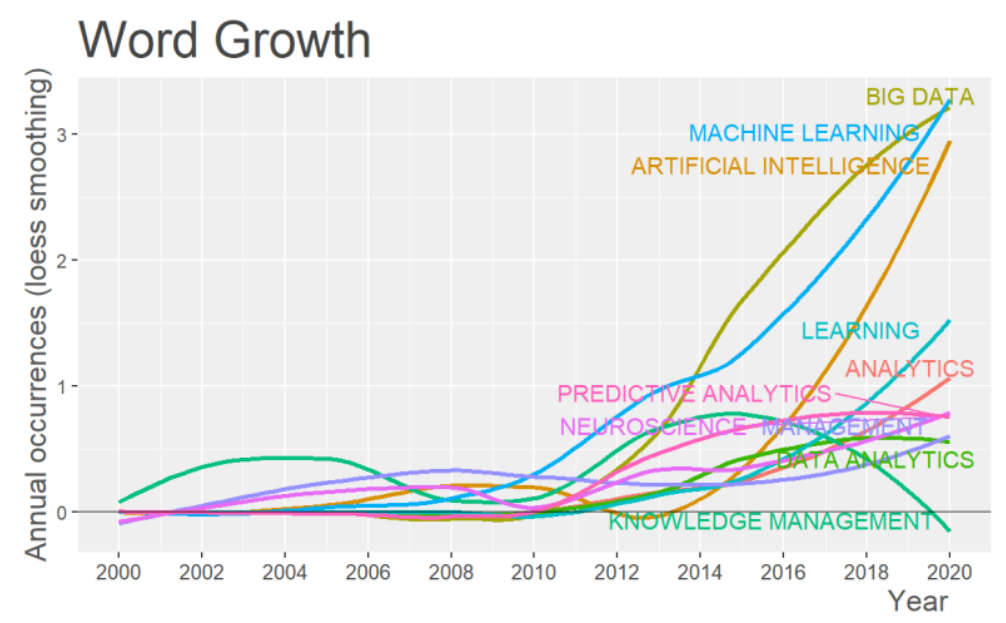

Figure 7: Word Graph

According to the graph, in the last 3 years the most searched words were Big Data, Machine Learning and Artificial Intelligence, evidencing a relevant growth since 2014. Until then all the research terms followed similar patterns. If we consider the interest $\mathrm{Al}$ has gained in the different countries that are adopting these techniques this could be considered quite logical. Also, "knowledge management" production rate tendency over the years did not follow the other subjects. It is interesting to observe the increase of the term "learning". One may assume that knowledge has been replaced by the term learning.

\subsection{Content Analysis}

Content analysis was performed using a chronological review of the subject within specific timespans to conduct the content analysis.

\subsubsection{From 2000 until 2004}

Within this timespan articles focused on machine learning and artificial intelligence for fuzzy models for scheduling problems and decisions processes in manufacturing diminishing human error (Nematii, 2002; Akyol, 2004); predicting gaming behaviour (Hinnar et al, 2004); behavioural simulation for coaching purposes (Summers, 2004); the role of mind in human and organizational behaviour (Seni and Seni, 2000; Setterret, 2002; Wolozin, 2004); planned (Bamberg, 2003) and consumer (Morik, 2002) behaviour. 


\subsection{2 $2005-2007$}

During this period articles focused on the emerging nature of knowledge management (Chua, 2005) and creating and sharing knowledge via the web using artificial intelligence (Cheung et al, 2005; Chen et al, 2005; Cracker and Coenen, 2006). Other papers found addressed using informatics and neurosciences to monitor behaviour (French et al, 2007; Monekosso and Remagnino, 2007).

\subsection{3 $2008-2010$}

In 2008, Michael Buttler concluded that knowledge has "plasticity". By that he meant that different stakeholders, including scholars and practitioners, perceived differently the development and application of neuromarketing. Understanding this could be crucial for knowledge creation and diffusion.

Human decision-making process can be modelled and controlled (Moffat and Medhurst, 2009) and the future can be forecasted, as market behaviour, market dynamics, market analysis, organizational strategies for volatile new markets, and profiling products and services which do not currently exist, but which markets are ready to accept (Zenobia et al, 2009).

In 2010, Faber and Peters, present the idea that Knowledge can be identified as the driving force behind human behaviour and that this behaviour can be changed through, amongst others, information technology. Seni and Seni (2010) proposed that cognition, in the broad sense, was not exclusive to living organisms since, certain kinds of social organizations, such as businesses, possess elementary cognitive capabilities by virtue of their structure and their functions. Both authors propose the idea of "sociocognitivity" based on neuroscience and biopsychology applied to any organization: (1) The theory of intelligence and of intelligent systems; (2) The neurological theory of memory as distributed, hierarchical neuronal systems; (3) The theory of cognitive action in general and of learning in particular.

\subsection{4 $2011-2013$}

Lin and colleagues (2012) presented a study on the emotional expression and artificial intelligence in the interaction between computers and humans in order to understand users' emotions.

Giraldo et al (2013) showed how computer science and cognitive neuroscience could be merged to propose an effective profiling scheme by content personalization through the identification of an individual's learning behaviour. In 2013, Aztiria and colleagues studied intelligent environments (IE) where the technology adapts its behaviour to the users, even anticipating their needs, preferences, or habits. The environment learns how to react to the actions and needs of the users.

\subsection{5 $2014-2016$}

Buttler et al (2016), explore the potential links between human biology and management and organization studies. The authors defined, what they considered to be a new field as "organizational cognitive neuroscience" (OCN). In their paper they revealed three clusters of activity, covering the fields of economics, marketing and organizational behaviour (considered as an outlier), which contributed to a greater understanding of the biological mechanisms that mediate choice and decision-making.

Human behaviour understanding plays a fundamental role in several innovative application domains such as smart video surveillance, ambient intelligence and content-based video information retrieval (Acampora et al, 2015). These authors propose a hierarchical architecture, based on a tracking algorithm, time-delay neural networks and fuzzy inference systems, aimed at improving the performance of current human behaviour analysis systems in terms of scalability, robustness and effectiveness in behaviour detection.

Lavín et al (2015) studied cooperative behaviour aiming to understand the motives behind people's subscription to a specific organization and whether their motivations are consistent with traditional experimental evidence about cooperative decision-making. Their results revealed a conjunction between structural frames and individual ethical values to be critical for explaining human cooperation.

Yu-Ping et al (2015) combined machine-learning techniques with functional neuroimaging data to characterize the set of processes that give rise to associations between brands and personality. They have showed that brand personality traits could be captured by the weighted activity across a widely distributed set of brain regions 
previously implicated in reasoning, imagery, and affective processing, i.e., brand personality traits appear to exist $a$ priori inside the minds of consumers.

Emotion is a cognitive process and is one of the important characteristics of human beings that makes them different from machines (Nahin et al, 2014). In their paper they have attempted to detect user emotions by analysing the keyboard typing patterns of the user and the type of texts (words, sentences) typed by them. To analyse data they've used several machine learning algorithms and manage to demonstrate above $80 \%$ accuracies in identifying emotions.

Smidts et al (2014) sketch the development of consumer neuroscience as a discipline and compare it to neuroeconomics. They also provide important insights into individual differences in decision-making and shed some light into the predicting decisions from brain activity and their reliability as measurements of consumer behaviour.

\subsubsection{7}

Kraczla (2017) undertook a research on human profiling based on personality traits. The rationale assumed that personality factors constitute a fundamental indicator of development potential of a particular person, and as such, it was possible to depict his/her functioning style in a job position and hence predict professional suitability in performing a given professional role.

Michie et al (2017) present the Human Behaviour-Change Project (HBCP) using artificial intelligence and machine learning. The purpose of their work was to (i) develop and evaluate a 'Knowledge System' that automatically extracts, synthesizes, and interprets findings from evaluation reports to generate new insights about behaviour change and improve prediction of intervention effectiveness and (ii) allow users, such as practitioners, policy makers and researchers, to query the system easily and efficiently.

Shmueli (2017) coined the term Behavioural Big Data (BBD), meaning the very large and rich multidimensional datasets on human behaviours, actions, and interactions, which have become available to companies, governments, and researchers. In his work he describes the BBD landscape and examines opportunities and critical issues that arise when applying statistical and data mining approaches to BBD and its implications.

\subsubsection{8}

According to Harteis et al (2018) preventing humans from committing errors is a crucial aspect of man-machine interaction and systems of computer assistance. In their work they use eye-tracking technology and automated face recognition to analyse / test persons' emotional reactions and cognitive load during a computer game and learning through trial and error. Results show a positive correlation between learning and emotions and that gaze behaviour and facial expressions inform about the errors that follow.

Chan et al (2018) use an approach to profiling brand image using functional magnetic resonance imaging. They compare consumers' brain responses during passive viewing of visual templates (photos depicting various social scenarios) and brain responses during active visualizing of a brand's image, and then they generate individual neural profiles of brand image that correlate with the participant's own self-report perception of those consumer brands. This neural profiling demonstrates the potential of using pattern analysis of neuroimaging data to study multisensory, nonverbal consumer knowledge and experience.

Fredriksson (2018) discuss big data in the theoretical light of organizational knowledge creation and decisionmaking in organizations. The findings suggest that creating new information and knowledge out of big data, and its use as support for decision-making in organizations, would enhance the quality and increase trustworthiness in decision-making. Goul (2018) addresses the importance of big data and predictive analytics on operations and manufacturing management and their utilization for capability building, and how this capability affects cost and operational performance.

Guha and Kumar (2018) study the digital footprints of consumers to understand and predict consumer behaviour (especially in the areas of cloud computing, internet of things and smart city, predictive manufacturing and 3-D printing and smart healthcare) and the associated challenges. 


\subsection{8 $2019-2020$}

Bleidorn and Hopwood (2019) use machine learning in psychological science to predict human behaviour through personality traits. Machine learning approaches to personality assessment have focused on the associations between social media and other digital records with established personality measures. This research aims to expand the potential of machine learning approaches to personality assessment by embedding it in a more comprehensive construct validation framework.

Constantin et al (2019) build a model to train and validate an artificial neural network to forecast the following year's value of economic sentiment using values of several economic indicators. Research on predicting European Economic Sentiment Indicator (ESI) using artificial neural networks is a starting point, with work on this subject almost inexistent, the reason being mainly that ESI is a composite of five sectorial confidence indicators and is not thought to be an emotional response to the interaction of the entrepreneurial population with different economic indicators.

Canhoto and Clear (2020) point out that artificial intelligence (AI) and machine learning (ML) may save money and improve the efficiency of business processes, but these technologies can also destroy business value, sometimes with grave consequences. They propose a new framework by which to map the components of an Al solution and to identify and manage the value-destruction potential of Al and ML for businesses.

Knox et al (2020) examine visions of 'learning' across humans and machines in a near-future of intensive data analytics. Building upon the concept of 'learnification', practices of 'learning' in emerging big data-driven environments are discussed in two significant ways: the training of machines, and the nudging of human decisions through digital choice architectures.

Steinberg (2020) introduce the possibility that, in the future, firms will be able to use big-data analysis to discover and offer consumers their individual reservation price (i.e., the highest price each consumer would be willing to pay, given their preferences and available income). This can generate some interesting benefits, such as a better situation in terms of equality of both welfare and resources, as well as increased social welfare. However, these benefits are countered by considerations of relational equality. This article takes up the market-failures approach as its basis to demonstrate what is wrong with using big data to personalize prices.

\section{Discussion and Further Studies}

From the systematic literature review undertaken and the bibliometric analysis done using VOSviewer and $\mathrm{R}$ programming, four emergent research areas were identified, namely, the use of big data for business efficiency, artificial swarm intelligence (through knowledge management and decision-making), personalized engagement marketing (customer/people connection) and the feeling economy (communicating with and for people), that are linked with the key issues of this paper.

Going back to the VOSviewer graph if we apply and $x$ axis (current state of research) and y axis (from past to future solutions) it seems that we are moving from an information era, regarding the usage of Big Data, Al and machine learning (hard issues) towards an era of the understanding of human behaviour and knowledge creation (soft issues). 


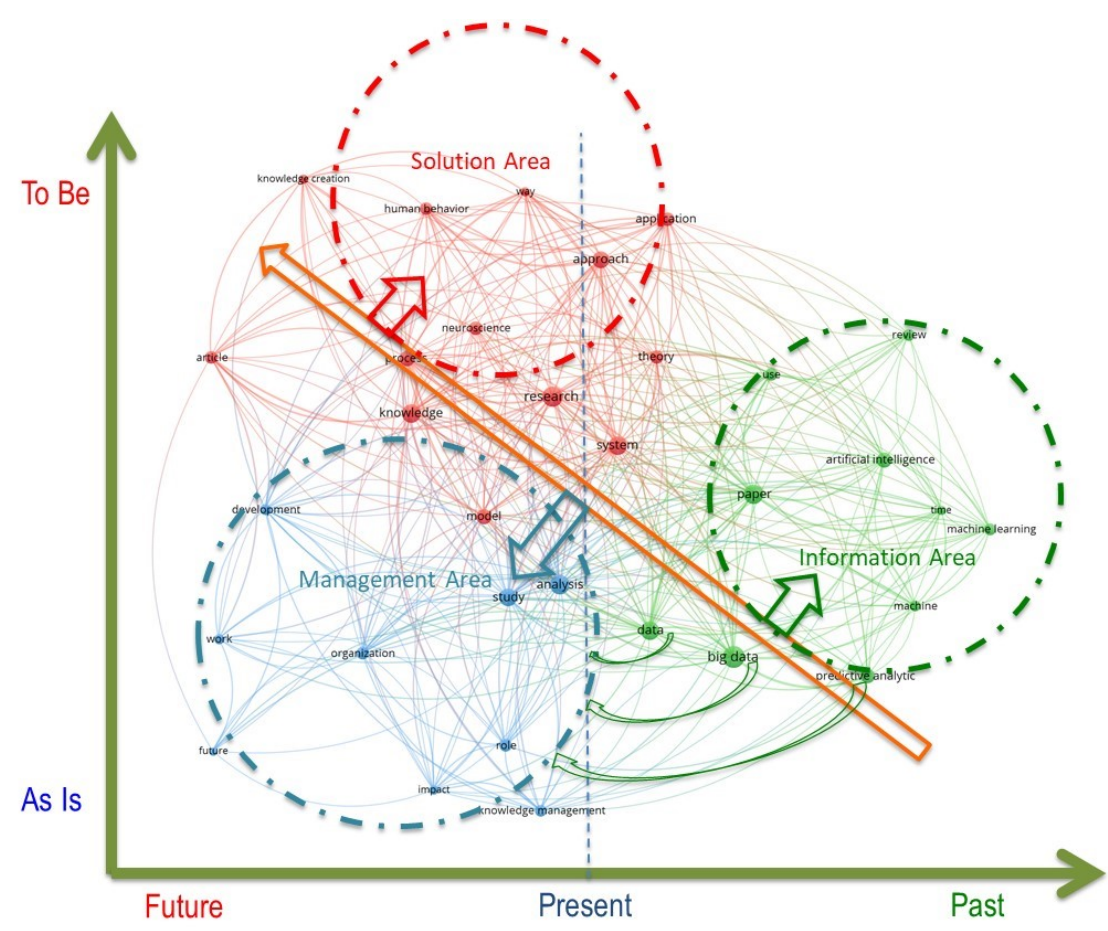

Figure 8: From Information to Management towards Knowledge Creation

Kumar, Yogesh and Dwivedib (2020) point out some interesting research questions addressing this field of research, amongst them, are some we consider relevant for understanding the challenges this field of research pose, namely:

- How can big data-driven research be used to explain digital service or technology adoption, usage, and impact behaviour?

- How can user engagement or disengagement can be measured and explained based on big data analytics?

- How can we develop typology of users or organizations based on user generated content in forums, social media and platforms?

- How can we explain relationships between organizations and other stakeholders (organizations, individuals, customers, suppliers, government, etc.) based on online content in platforms and e-markets and their impacts on engagement or disengagement?

- How can we model adverse impacts of disruptive technologies like artificial intelligence, blockchain, internet of things based on usage behaviour or user generated content?

- How can theories be developed to explain grand socio-political problems and challenges of like pandemic management, sustainable development goals, political harmony, etc.?

The journey over the past 20 years of research demonstrated that we have started on managing data, moving forward to having information that was transformed into intelligence. Intelligence can then be transformed into knowledge. But managing knowledge is no longer sufficient, since now we possess technologies that allow us to create knowledge from knowledge, so we are moving towards a fuzzier understanding of the human behaviour. In summary we are moving from data-driven organizations towards the feeling economy (from hard issues such as analytics towards soft issues such as people).

\subsection{Organizational Efficiency (data-driven)}

Artificial intelligence helps the predictive ability of organizations (Davenport et al, 2020). Al has recently become popular because it provides a cheap way to make predictions about complex problems based on examples in historical data that a company might already have. This is possible through machine learning (ML). $\mathrm{ML}$ is a key issue of this paper, as is defined as "a set of methods that can automatically detect patterns in data, and then use the uncovered patterns to predict future data, or to perform other kinds of decision making under uncertainty" (Murphy, 2012). 


\subsection{Artificial Swarm Intelligence (ASI)}

Schools of fish, flocks of birds and ants' colonies demonstrate collective intelligence, since they are capable of making decisions that go beyond the knowledge of individuals in the group (Sulis, 1997). According to Sulis, individuals within the group base their decisions on self-organized local interactions with group members. Mimicking nature for understanding organizations is not new. The emergent decision-making process found in honeybee swarms provides a powerful analogue for how human brains make complex decisions and allowed ASI to enable groups of networked humans to function as a unified intelligence (Rosenberg, L., 2016). This field of research can be found at the top quadrant of Figure 8. "ASI draws from the methods of achieving collective intelligence found in biological swarms to enable human groups to form a single emergent intelligence" (Metcalf et al, 2019, pp. 85).

\subsection{Personalized Engagement Marketing}

Personalization is often presented and studied alongside customization, as they are related concepts, although differing in application (Kumar, et al; 2019). Personalization derives from the business strategy (based on data collection from individual preferences) whereas customization originates from the customers preferences (for example you can customize a car, choosing the colour and specific features). According to Kumar and colleagues $(2019$, p. 151) "firms are able to leverage individual customer information and Al technology to provide curated products and services. The Al technology can facilitate real-time learning and help managers improve customer value proposition over time. Such a strategy of curated products that provide increasing value to customers will form the basis of customer retention and sustainable competitive advantage". The step forward will be using the knowledge gained through Al to trace profiles of human behaviour and predicting more precise preferences.

\subsection{The Feeling (Emotions) Economy}

"The Feeling Economy is an economy in which the total employment and wages attributable to feeling tasks exceed the total employment and wages attributable to thinking or mechanical tasks" (Huang et al, 2019, pp. 44-45). According to these authors in the emerging of the Feeling Economy, the interpersonal, empathetic, feeling tasks of a job, such as communicating with people inside and outside the organization, establishing and maintaining interpersonal relationships, and selling to or influencing others, tend to be more important than thinking tasks and mechanical tasks, for both employees and consumers. Huang and colleagues add that this Feeling Economy will fully overtake the Thinking Economy (jobs that require analysing data and making decisions) by the year 2036 .

Main challenges derived from this are: (1) understanding the nature of future jobs and the required skills, (2) considering that humans and machines must collaborate as a "team", (3) anywhere-anytime interaction with internal and external consumers addressing their emotional needs.

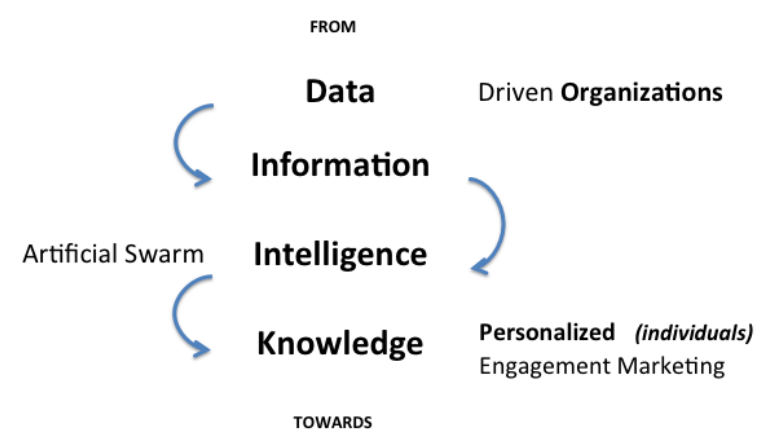

The Feeling Economy

Figure 1: The Journey from Data to People

There are many challenges for researchers in this field. Deep Learning, a key technique used by most Al systems, and the study of the human brain (emotion versus reason) are inherently black boxes, making it very complicated to fully comprehend. Also, there is a fear, that, in a similar manner as the automation of manufacturing processes has resulted in the loss of blue-collar jobs, the rising use of Al will result in less need for white-collar employees and even high-qualified professional jobs, resulting in a resistance for adopting ASI. Nevertheless, researchers 
have demonstrated that ASI addresses the limitations associated with group decision-making, amplifying the intelligence of human groups, and facilitating better business decisions. Also, the use of Al, machine learning and neurosciences, pose unique ethical, legal, and philosophical challenges that will need to be addressed.

\section{Conclusions}

The research conducted by the authors included a systematic and bibliometric literature review, of the past 20 years on the study of knowledge management related to artificial intelligence, machine learning and the understanding of human behaviour through neurosciences approaches. The research showed the past, present and future of this field of research and the linkages between the different terms that were reviewed.

The paper achieved the proposed goal by mapping what is known about the key issues and "understanding how artificial intelligence and machine learning applied to human behaviour has been treated regarding predictive analytics and human organizational behaviour analysis".

The main limitation of the study lies in the information sources considered. Papers were selected from B-On and WoS databases, and as such, grey literature was not included, thus many interesting studies may be omitted.

The main conclusions of the study were that we are moving from business efficiency (data-driven organisations) towards business efficacy by using knowledge to create knowledge. Knowledge that occurs from managing information (hard issues) towards knowledge that evolves from the understanding the collective (swarm) and individual intelligence, through the application of neurosciences tools, towards knowledge creation within the feeling economy.

The human being is quite complex and makes decisions that are not always rational, often influenced by emotional or situational factors. Assuming that Al and Machine Learning are based on rational models, are these methods the best tools for predicting human behaviour? Also based on Al and ML's ability to analyse and sort a lot of information, namely in the digital relationship between people and organisations, are these the best tools to anticipate, manage and generate organizational knowledge?

Further studies should be developed in this field of research addressing the questions posed along this research article, especially empirical works focussing the journey from data to people.

\section{Acknowledgments}

This research work is financed by national funds through FCT - Foundation for Science and Technology, I.P., under the project «UIDB/04005/2020».

\section{References}

Acampora, G., Pedrycz, W. \& Vitiello, A. (2015) A hierarchical neuro-fuzzy architecture for human behavior analysis, Information Sciences, v. 310, p. 130-148.

Akyol, D. E. (2004) Application of neural networks to heuristic scheduling algorithms, Computers \& Industrial Engineering, v. 46, n. 4, p. 679-696.

Aztiria, A., Augusto, J., Basagoiti, R., Izaguirre, A. \& Cook, D.J. (2013). Learning Frequent Behaviors of the Users in Intelligent Environments, IEEE Transactions on Systems, Man \& Cybernetics, v. 43, n.6, p. 1265-1278.

Bamberg, S., Ajzen, I. \& Schmidt, P. (2003) Choice of Travel Mode in the Theory of Planned Behavior: The Roles of Past Behavior, Habit, and Reasoned Action, Basic \& Applied Social Psychology, v. 25 Issue 3, p. 175-188.

Bleidorn, W. \& Hopwood, C. J. (2019) Using Machine Learning to Advance Personality Assessment and Theory, Personality \& Social Psychology Review (Sage Publications Inc.), v. 23; Issue 2; p. 190-203.

Butler, M. (2008) Neuromarketing and the perception of knowledge, Journal of Consumer Behaviour, v. 7 Issue 4/5, p. 415419.

Butler, M., O’Broin, H., Lee, N. \& Senior, C. (2016). How Organizational Cognitive Neuroscience Can Deepen Understanding of Managerial Decision-making: A Review of the Recent Literature and Future Directions, International Journal of Management Reviews, v. 18 Issue 4, p. 542-559.

Canhoto, A. I. \& Clear, F. (2020). Artificial intelligence and machine learning as business tools: A framework for diagnosing value destruction potential, Business Horizons, v. 63; 2; p. 183-193.

Chan, H.Y., Boksem, M. \& Smidts, A. (2018). Neural Profiling of Brands: Mapping Brand Image in Consumers' Brains with Visual Templates, Journal of Marketing Research (JMR), v. 55 Issue 4, p. 600-615.

Chen, A. \& Edginton, T. (2005). Assessing Value in organizational knowledge creation: considerations for knowledge workers, MIS Quarterly, v. 29 Issue 2, p. 279-309. 
Cheung, W.K. \& Liu, J. (2005). On knowledge grid and grid intelligence: A survey, Computational Intelligence, v. 21 Issue 2, p. 111-129.

Chua, A. (2005). The design and implementation of a simulation game for teaching knowledge management, Journal of the American Society for Information Science \& Technology, v. 56 Issue 11, p. 1207-1216.

Constantin, I., Ploae, C., Meinic, L., Cotumbra, M., Gurau, A. \& Coman, A. (2019). Sustainability through the Use of Modern Simulation Methods-Applied Artificial Intelligence, Sustainability, Switzerland, v. 11 Issue 8.

Coughlan M., Cronin P. \& Ryan F. (2007). Step-by-step guide to critiquing research. Part 1: quantitative research. Br J Nurs v. 16 , Issue 11 , p. 658-663.

Craker, B. \& Coenen, F. (2006). The Knowledge Bazaar, Knowledge-Based Systems, Al 2005 SI, v. 19, Issue 5, p. 341-347.

Cronin, P., Ryan, F. \& Coughlan, M. (2008). Undertaking a literature review: A step-by-step approach, British Journal of Nursing, v. 17, Issue 1.

Davenport, T., Guha, A., Grewal, D. \& Bressgott, T. (2020). How artificial intelligence will change the future of marketing. Journal of the Academy of Marketing Science v. 48, p. 24-42.

Delloitte Insights. (2019). Future in the balance? How countries are pursuing an Al advantage Insights from Deloitte's State of $A l$ in the Enterprise, $2^{\text {nd }}$ Edition survey.

Faber, N., Peters, K., Maruster, L., van Haren, R. \& Jorna, R. (2010). Sense Making of (Social) Sustainability, A Behavioural and Knowledge Approach, International Studies of Management \& Organization, v. 40 Issue 3, p. 8-22.

Fredriksson, C. (2018). Big data creating new knowledge as support in decision-making: practical examples of big data use and consequences of using big data as decision support, Journal of Decision Systems, v. 27 Issue 1, p. 1-18.

French, L. \& Pavlidis, P. (2007). Informatics in neuroscience, Briefings in Bioinformatics, v. 8 Issue 6, p. 446-456.

Giraldo, J. G., Jiménez B. \& Jovani, A. (2013). Adaptive User Profiling Scheme Using Brain Imaging, Revista Lasallista de Investigación, v. 10, Issue 2, p. 77-83.

Goul, M. (2018). Big Data and Predictive Analytics and Manufacturing Performance: Integrating Institutional Theory, Resource-Based View and Big Data Culture, MIS Quarterly Executive, v. 30 Issue 2, p. 341-361.

Guha, S. \& Kumar, S. (2018). Emergence of Big Data Research in Operations Management, Information Systems, and Healthcare: Past Contributions and Future Roadmap, Production \& Operations Management, v. 27, Issue 9, p. 17241735.

Haenlein, M. \& Kaplan, A. (2019). A Brief History of Artificial Intelligence: On the Past, Present, and Future of Artificial Intelligence, California Management Review, v. 61, Issue 4, p. 5-14.

Harteis, C., Fischer, T. \& Töniges, B. (2018). Do We Betray Errors Beforehand? The Use of Eye Tracking, Automated Face Recognition and Computer Algorithms to Analyse Learning from Errors, Frontline Learning Research, v. 6, Issue 3, p. 37-56.

Hinnar, R. S., Young, C. A. \& Corsun, D. L. (2004). Las Vegas Locals as Gamblers and Hosts to Visiting Friends and Family: Characteristics and Gaming Behavior, UNLV Gaming Research \& Review Journal, v. 8 Issue 2, p. 39-48.

Hoeschl H.C. \& Barcellos V. (2006). Artificial Intelligence and Knowledge Management. In: Bramer M. (eds) Artificial Intelligence in Theory and Practice. IFIP AI 2006. IFIP International Federation for Information Processing, v. 217. Springer, Boston, MA . https://doi.org/10.1007/978-0-387-34747-9 2

Huang, M. H., Rust, R. \& Maksimovic, V. (2019). The Feeling Economy: Managing in the Next Generation of Artificial Intelligence (AI), California Management Review, v. 61, Issue 4, p. 43-65.

Knox, J., Williamson, B. \& Bayne, S. (2020). Machine Behaviourism: Future Visions of 'Learnification' and 'Datafication' across Humans and Digital Technologies, Learning, Media and Technology, v. 45, Issue 1 p. 31-45.

Kraczla, M. (2017). Personality profiling according to the big five model by P. T. Costa and R. R. Mccrae: Comparison analysis of managers and specialists. Regional Formation \& Development Studies, Issue 22, p. 77-91.

Kumar, T. \& Ajay, K. (2019). K-RCC: A novel approach to reduce the computational complexity of KNN algorithm for detecting human behavior on social networks, Journal of Intelligent \& Fuzzy Systems, v. 36 Issue 6, p. 5475-5497.

Kumar, A., Yogesh, K, \& Dwivedi, K. (2020). Theory building with big data-driven research - Moving away from the "What" towards the "Why", International Journal of Information Management, 54

https://doi.org/10.1016/j.ijinfomgt.2020.102205.

Lavín, C., Espejo, A., Bravo, D. \& Morales, S. (2015). What makes people decide to pay more? Understanding cooperation in the context of an alternative food network, Asian Journal of Social Psychology, v. 18, Issue 3, p. 236-245.

Metcalf, L., Askay, D. \& Rosenberg, L. (2019). Pooling Knowledge through Artificial Swarm Intelligence to Improve Business Decision Making, California Management Review, v. 61, Issue 4, p. 84-109.

Michie, S., Thomas, J. \& Johnston, M. (2017) The Human Behaviour-Change Project: harnessing the power of artificial intelligence and machine learning for evidence synthesis and interpretation. Implementation Sci, v. 12, 121 (2017). https://doi.org/10.1186/s13012-017-0641-5

Moffat, J. \& Medhurst, J. (2009). Modelling of human decision-making in simulation models of conflict using experimental gaming, European Journal of Operational Research, v. 196, Issue 3, p. 1147-1157.

Moher, D.; Liberati, A.; Tetzlaff, J. \& Altman, D. (2009). Preferred reporting items for systematic reviews and metaanalyses: the PRISMA statement, BMJ; 339 doi: https://doi.org/10.1136/bmj.b2535

Monekosso, D. N. \& Remagnino, P. (2007). Monitoring behavior with an array of sensors, Computational Intelligence, v. 23 Issue 4, p. 420-438. 
Morik, K., Hüppe, C. \& Unterstein, K. (2002). End-user access to multiple sources: incorporating knowledge discovery into knowledge management, International Journal of Intelligent Systems in Accounting Finance \& Management, v. 11 Issue 4, p. 201-214.

Murphy, K. (2012). Machine Learning: A Probabilistic Perspective, Cambridge, MA: MIT Press

Nahin, A.F.M., Alam, M. J., Mahmud, H. \& Hasan, K. (2014). Identifying emotion by keystroke dynamics and text pattern analysis, Behaviour \& Information Technology, v. 33 Issue 9, p. 987-996.

Nemati, H. R., Steiger, D., Iyer, L. \& Herschel, R. (2002). Knowledge warehouse: an architectural integration of knowledge management, decision support, artificial intelligence and data warehousing, Decision Support Systems, v. 33, Issue 2, p. $143-161$.

Rosenberg, L. (2016). Artificial Swarm Intelligence, a human-in-the-loop approach to A.I., Proceedings of the Thirtieth AAAI Conference on Artificial Intelligence (AAAI2016), Phoenix, Arizona. p. 4381-4382.

Seni, D. A. \& Seni, A. G. (2000). Les neurosciences modernes présagent-elles un nouveau modèle de la cognition des organisations? , Gestion, v. 27, Issue 6, p. 131-144.

Seni, D. A. \& Seni, A. G. (2010). Do Modern Neurosciences Herald a New Cognition Model for Companies? Gestion 2000, Vol. 27 Issue 6, p. 131-144.

Shmueli, G. (2017). Analyzing Behavioral Big Data: Methodological, practical, ethical, and moral issues, Quality Engineering, . 29 Issue 1, p57-74. 18p.

Simsek, Z., Vaara, E., Paruchuri, S., Nadkarni, S. \& D. Shaw, J.D. (2019). From the Editors: New Ways of Seeing Big Data, Academy of Management Journal, v. 62, Issue 4, p. 971-978.

Smidts, A., Hsu, M., Sanfey, A.G. et al. (2014). Advancing consumer neuroscience. Mark Lett v. 25, p. 257-267. https://doi.org/10.1007/s11002-014-9306-1

Steinberg, E. (2020). Big Data and Personalized Pricing, Business Ethics Quarterly, v. 30, Issue 1, p. 97-117.

Sterrett, S. G. (2002). Too many instincts: contrasting philosophical views on intelligence in humans and non-humans, Journal of Experimental \& Theoretical Artificial Intelligence, v. 14, Issue 1, p. 39-60.

Sulis, W. (1997). Fundamental Concepts of Collective Intelligence, Nonlinear Dynamics, Psychology, and Life Sciences, v. 1, Issue 1, p. 35-53.

Summers, G. J. (2004). Today's business simulation industry, Simulation \& Gaming, v. 35, Issue 2, p. 208-241.

Tranfield, D., Denyer, D. \& Smart, P. (2003). Towards a Methodology for Developing Evidence-Informed Management Knowledge by Means of Systematic Review, British Journal of Management, v. 14, Issue 3, p. 207-222.

Wolozin, H. (2004) The Human Mind, Institutions, and Economic Behavior, Journal of Economic Issues (Association for Evolutionary Economics), v. 38, Issue 2, p. 563-570.

Yu-Ping C., Nelson, L. D. \& Ming H. (2015). From "Where" to "What": Distributed Representations of Brand Associations in the Human Brain, Journal of Marketing Research (JMR), v. 52, Issue 4, p. 453-466.

Zenobia, B., Weber, C. \& Daim, T. (2009). Artificial markets: A review and assessment of a new venue for innovation research, Technovation, v. 29, Issue 5, p. 338-350. 